\title{
Design and Testing of Improved Spacesuit Shielding Components
}

\author{
J.Ware, J.Ferl \\ ILC Dover, Frederica, DE \\ J.W.Wilson \\ NASA Langley Research Center, Hampton, VA \\ M.S. Clowdsley \\ NRC/NASA Langley Research Center, Hampton, VA \\ G. de Angelis, J. Tweed \\ Old Dominion University, Norfolk, VA \\ C.J. Zeitlin \\ Lawrence Berkeley National Laboratory, Berkeley, CA
}

Copyright () 2002 Society of Automotive Engineers, Inc.

\begin{abstract}
In prior studies of the current Shuttle Spacesuit (SSA), where basic fabric lay-ups were tested for shielding capabilities, it was found that the fabric portions of the suit give far less protection than previously estimated due to porosity and non-uniformity of fabric and LCVG components. In addition, overall material transmission properties were less than optimum. A number of alternate approaches are being tested to provide more uniform coverage and to use more efficient materials. We will discuss in this paper, recent testing of new material layups/configurations for possible use in future spacesuit designs.
\end{abstract}

\section{INTRODUCTION}

The construction of the International Space Station (ISS) requires 1500 hours of extravehicular activity (EVA) during construction and 400 hours per year in operations and maintenance. The orbit at 51.6 degrees inclination is in a highly variable radiation environment driven by solar activity. Solar particle events will enter this region, especially during an associated geomagnetic storm. The geomagnetic storm conditions also increase the trapped electron environment by up to four orders of magnitude; this electron enhancement can persist for several days. Although safety demands that such events be avoided if possible, work activity may not allow the astronaut to seek shelter in a timely fashion and the transmission properties of the basic suit are critical to astronaut safety.
These exposures will add to the usual quiet-time exposures to trapped protons and electrons and galactic cosmic rays experienced by the astronaut.

In past calculations of spacesuit exposures [1], the material lay-ups were converted into equivalent amounts of aluminum by scaling with the ratio of range of a $50 \mathrm{MeV}$ proton in aluminum to the range in the specific material and calculations were made for penetration in the equivalent aluminum. There are three concerns with this approach: 1) the equivalent aluminum scale factor depends on the proton energy and the assumed $50 \mathrm{MeV}$ is not accurate for estimation for minimum penetration particles; 2) the water filled cooling tubes of the Liquid Cooling and Ventilation Garment (LCVG) cover only 40 percent of the surface area and the homogenization with the remaining fabric over-estimates the protection properties over 60 percent of the area; and 3) many components of the fabric lay-up are inhomogeneous structures and may not be well represented by an average areal density. In a previous work, we found in experimental testing [2] that the protection qualities are about half of that assumed in prior studies.

Though at this point no official re-design/fabric replacement effort has been initiated, this study begins a search for materials that offer improved radiation protection for possible use in future spacesuit construction. A guiding principle is to seek replacement materials that have higher hydrogen content and are more uniform than those in the present spacesuit. A series of 
new materials have been selected and preliminary testing on their transmission properties has begun. We will discuss herein the test apparatus and methods as well as the current status of this material selection process.

\section{BASIC SPACESUIT CONFIGURATION}

The fabric components of the SSA are manufactured by ILC Dover, Inc. for use in the space program. The basic components [3] are shown in fig. 1. Not shown in the figure is the life support system held mainly in a backpack attached to the Hard Upper Torso (HUT). We are mainly concerned herein with the most easily penetrated portions of spacesuit, the arm assembly and Lower Torso Assembly (LTA) consisting of fabric layers and the Liquid Cooling and Ventilation Garment (LCVG) consisting of fabric and the water filled cooling tubes. The basic lay-up of the fabric and LCVG are shown in fig. 2.

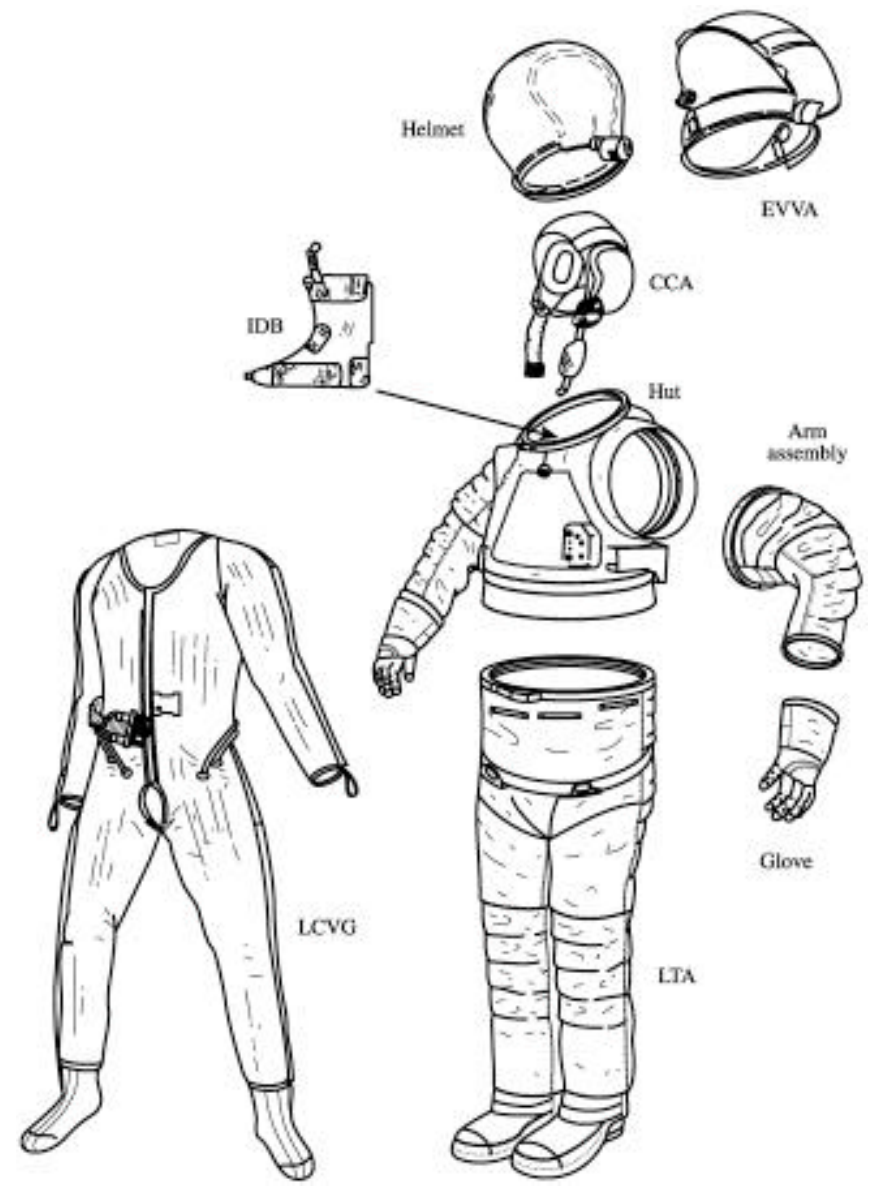

Fig. 1. Basic components of the Shuttle spacesuit.

Radiation penetration is of greatest importance when the environment contains low energy particles with limited penetration power. Most environmental components contain such particles and they are often the most intense component. They are only of concern for tissues that are poorly shielded and not of concern within a space vehicle assembly such as the Shuttle or ISS or for organs deep within the body. The basal layer of the skin is somewhat sensitive to radiation and therefore of concern in a lightly shielded spacesuit in an intense and low-energy environment.

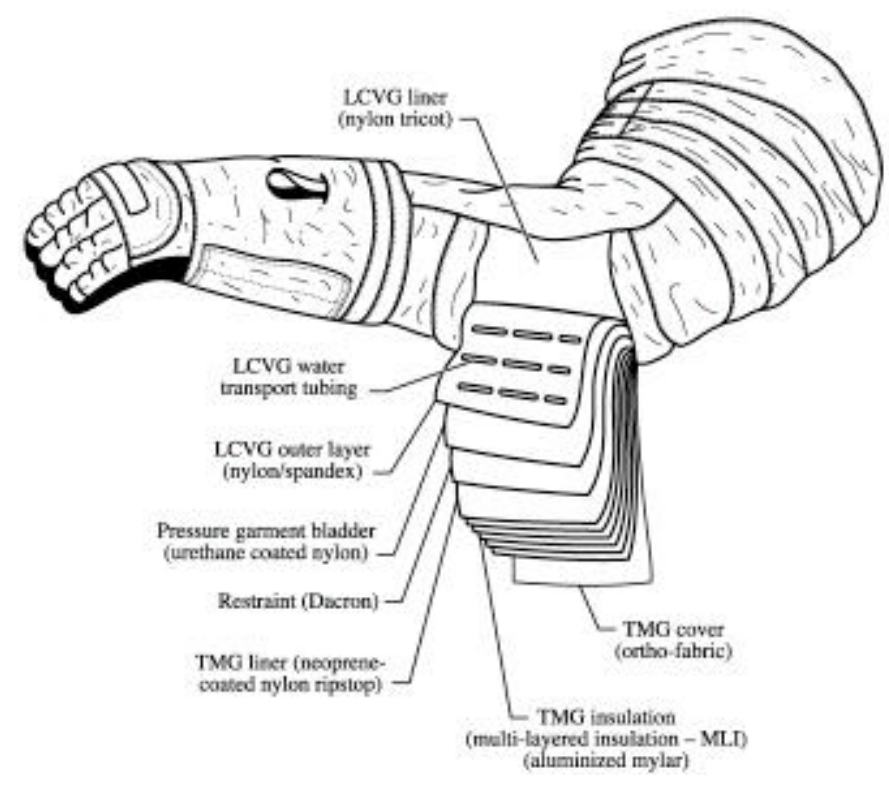

Fig. 2. Cross section of material lay-up.

The material lay-up for the SSA arm assemblies and LTA, including the inner LCVG, is given in table 1. The outer layer of the SSA, the Thermal Micrometeoroid Garment (TMG), protects the astronaut and the inner layers of the SSA from extreme temperatures and puncture by micrometeoroids. This layer is composed of Ortho-fabric, multiple layers of reinforced aluminized mylar and neoprene coated nylon ripstop. In the arm and leg and flexing areas of the SSA there are 5 layers of reinforced aluminized mylar. In static areas such as over the HUT, there are 7 layers. Below the TMG is the pressure restraint and bladder layer. The restraint, with its axial webbings, carries the loads imposed by pressurization and manned use and provides structural integrity for the SSA. The restraint is fabricated from Dacron ${ }^{\circledR}$ fabric. The bladder provides gas retention and is fabricated from urethane coated nylon fabric. The LCVG forms the innermost SSA layer worn against the astronaut's skin. The LCVG provides cooling and ventilation for the comfort of the astronaut. The garment is fabricated from a multifilament nylon/Spandex knit fabric into which is woven the ethylene vinyl- acetate tubes filled with water. The LCVG also contains a nylon tricot liner layer. 
Table 1. Material lay-up of the spacesuit fabric and water filled tube $[1,3]$.

\begin{tabular}{|l|l|}
\hline Material & $\begin{array}{l}\text { Areal density, } \\
\mathrm{g} / \mathrm{cm}^{2}\end{array}$ \\
\hline Ortho-fabric Gore-Tex $® /$ Nomex/Kevlar & 0.049 \\
Reinforced Aluminized Mylar & 0.014 \\
Neoprene Coated nylon Ripstop & 0.028 \\
Dacron® Polyester & 0.021 \\
Urethane Coated nylon Ripstop & 0.014 \\
Nylon/Spandex/water/ethylene vinyl & 0.154 \\
acetate & \\
\hline
\end{tabular}

\section{MATERIAL SAMPLES}

Material samples were chosen with two considerations. First is to establish a baseline for current spacesuit components. Second is to test new concepts relative to the baseline. In a previous report [2], we established a baseline for the TMG/LCVG lay-up with the water filled cooling tubes in our prior study. In the present study, we will establish a baseline for the HUT in preparation for possible future improvements. In addition, alternative TMG, restraint and bladder, and LCVG lay-ups will be considered.

The first two target lay-ups are the HUT related materials given in table 2. The fiberglass structure provides pressure retention in the upper torso area, there is no restraint and bladder layer. Therefore the baseline lay-up consists of an LCVG layer, fiberglass, and the HUT TMG layer. First the fiberglass structure was tested with the HUT TMG of the current space suit over an experimental LCVG. This was followed by a test of the fiberglass with an experimental HUT TMG over the same experimental LCVG. The fiberglass and HUT TMG target samples tested are shown in figure 3 .

The SSA TMG is of a different lay-up in the shoulder area than the standard arm assembly and LTA lay-up. In the shoulder area, there is an additional layer of Gore-Tex ${ }^{\circledR}$ fabric under the neoprene coated nylon ripstop. A replacement for the arm/leg TMG is also proposed in table 3 as target ILC 203. Note that this target, ILC 203, is also being used as an experimental replacement for the HUT TMG. The 5 mylar layers of the original design are replaced by 4 layers of polyethylene film which has improved radiation shielding characteristics. In this test, the polyethylene film was not coated with a reflective surface as might be necessary to replace the reflective properties of the aluminized mylar. The TMG target samples are shown in figure 4.
Table 2. Material lay-up of the current SSA HUT.

\begin{tabular}{|c|c|c|c|}
\hline $\begin{array}{c}\text { Target } \\
\text { No. }\end{array}$ & Description & Lay-up & $\begin{array}{l}\text { Areal density, } \\
\mathrm{g} / \mathrm{cm}^{2}\end{array}$ \\
\hline $\begin{array}{l}\text { ILC } \\
102\end{array}$ & $\begin{array}{l}\text { TMG/ } \\
\text { Fiberglass }\end{array}$ & $\begin{array}{l}1 \text { Orthofabric } \\
7 \text { Mylar } \\
1 \text { Neoprene } \\
1 \text { fiberglass } \\
\text { 1Thick Spectra } \\
1 \text { Thin Spectra }\end{array}$ & $\begin{array}{l}0.0499 \\
0.0218 \\
0.0273 \\
0.48 \\
\\
0.0355 \\
0.0073\end{array}$ \\
\hline $\begin{array}{l}\text { ILC } \\
203 \\
\text { ILC } \\
101 \\
\text { ILC } \\
301 \\
\end{array}$ & $\begin{array}{l}\text { Fiberglass } \\
\text { LCVG }\end{array}$ & $\begin{array}{l}\text { 1 Orthofabric } \\
4 \text { LLPE } \\
1 \text { Neoprene } \\
1 \text { fiberglass } \\
\text { 1Thick Spectra } \\
1 \text { Thin Spectra }\end{array}$ & $\begin{array}{l}0.0485 \\
0.0417 \\
0.0265 \\
\\
0.48 \\
\\
0.0355 \\
0.0073\end{array}$ \\
\hline
\end{tabular}

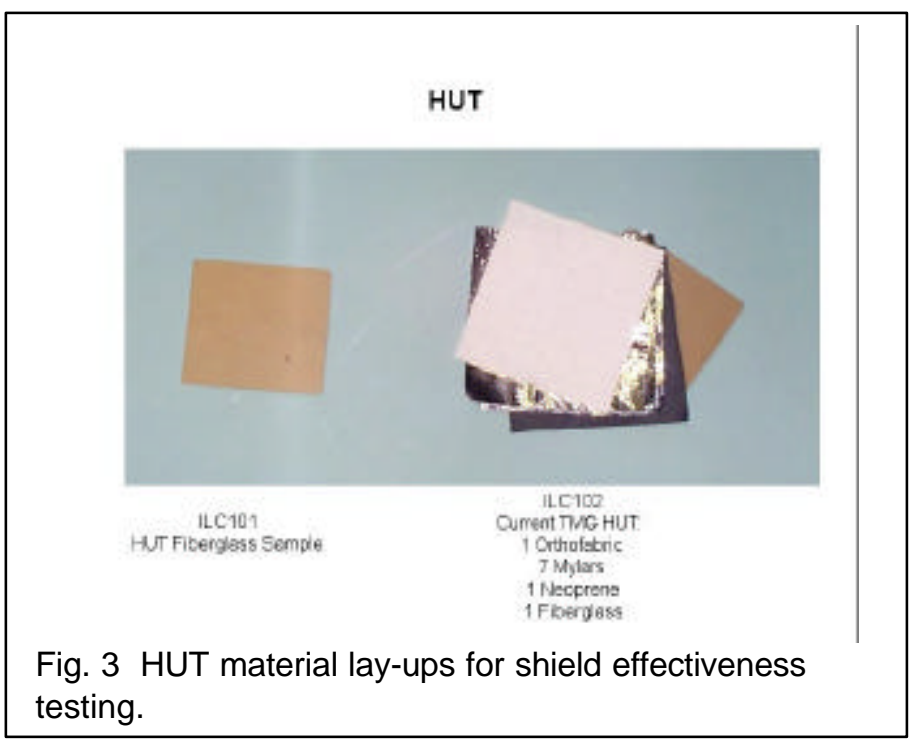

Table 3. Material lay-up for current and proposed TMG.

\begin{tabular}{|c|l|l|l|}
\hline $\begin{array}{c}\text { Target } \\
\text { No. }\end{array}$ & Description & Lay-up & $\begin{array}{l}\text { Areal density, } \\
\mathrm{g} / \mathrm{cm}^{2}\end{array}$ \\
\hline ILC & Current TMG & 1 Orthofabric & 0.0490 \\
201 & Arms/Legs & $\begin{array}{l}5 \text { Mylar } \\
\text { 1 Neoprene }\end{array}$ & 0.0150 \\
& & 0.0263 \\
\hline ILC & Current TMG & 1 Orthofabric & 0.0485 \\
202 & Shoulders & 5 Mylar & 0.0150 \\
& & 1 Neoprene & 0.0264 \\
& & 1 Gore-Tex ${ }^{2}$ & 0.0330 \\
\hline ILC & Proposed & 1 Ortho-fabric & 0.0485 \\
203 & TMG & 4 LLPE & 0.0417 \\
& & 1 Neoprene & 0.0265 \\
\hline
\end{tabular}




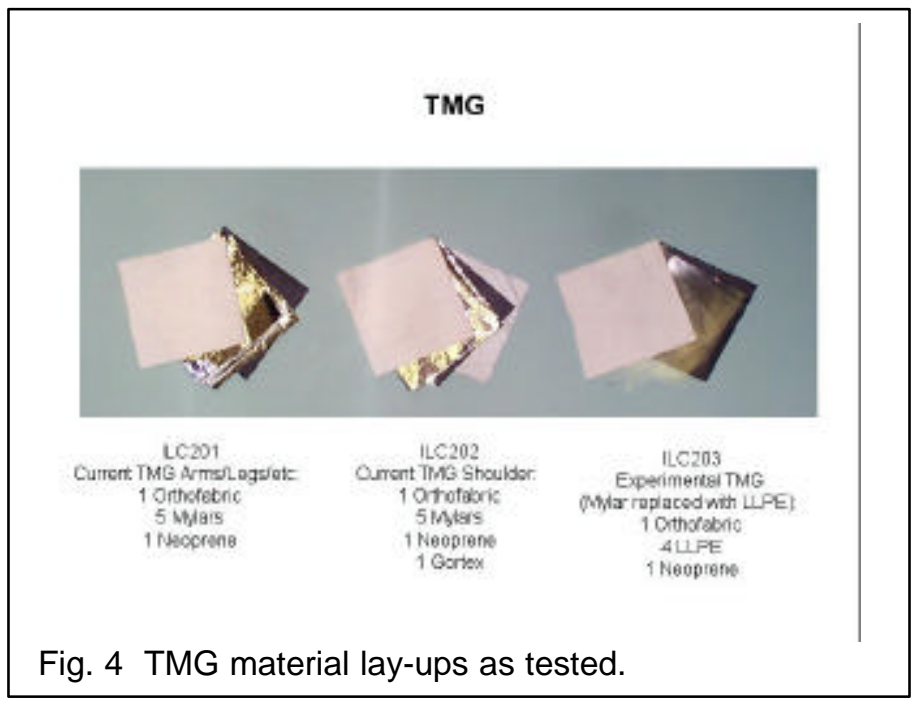

The LCVG inner garment with the liquid cooling tubes was a poor performing shield due to porosity and the nonuniformity of the cooling tubes (see figure 2). The transmission characteristics of the current LCVG were fully characterized in our prior report [2]. There are two proposed lay-ups for LCVG components, ILC 301 and ILC 302 , as given in table 4 . In the first proposed lay-up, the fabric components of the original LCVG are replaced with Spectra ${ }^{\circledR}$ fiber based material (Spectra ${ }^{\circledR}$ is a high-density polyethylene fiber). A heavier Spectra ${ }^{\circledR}$ knit fabric replaces the nylon/Spandex net and a more light-weight Spectra ${ }^{\circledR}$ knit fabric replaces the nylon liner. In this test, no water tubes were woven into the fabric, thereby representing areas of the current LCVG design that have no water cooling. The use of polyethylene components as opposed to the usual LCVG materials (Spandex/Nylon) will improve the atomic interaction properties. The second proposed LCVG lay-up represents a water cooling jacket concept. In this concept, the original LCVG nylon/Spandex net component with woven water tubes is replaced with layers of a urethane coated nylon fabric and urethane film formed into channels to carry water throughout the component. The original LCVG liner component is replaced with the light-weight Spectra ${ }^{\circledR}$ knit fabric. The water cooling jacket is a more uniform structure compared to the water cooling tubes and the water fill will add to the protection properties and will have to be quantified if put into use. The LCVG targets are shown in figure 5.

There are four proposed lay-ups for restraint and bladder components; ILC 303a, ILC 303b, ILC 304a, and ILC 304b; as shown in table 4 . Proposed replacements for the Dacron ${ }^{\circledR}$ restraint are a woven Spectra ${ }^{\circledR}$ fabric and a Spectra ${ }^{\circledR}$ webbing material. A proposed replacement for the urethane coated nylon bladder is a polyethylene film. The four proposed restraint and bladder lay-ups are the possible combinations of each Spectra ${ }^{\circledR}$ restraint with either current urethane coated nylon bladder cloth or polyethylene film bladder. The restraint and bladder targets are shown in figure 5 .

Table 4. Material lay-up for current and proposed LCVG and restraint and bladder.

\begin{tabular}{|c|c|c|c|}
\hline $\begin{array}{l}\text { Target } \\
\text { No. }\end{array}$ & Description & Lay-up & $\begin{array}{l}\text { Areal } \\
\text { density, } \\
\mathrm{g} / \mathrm{cm}^{2}\end{array}$ \\
\hline $\begin{array}{l}\text { ILC } \\
301\end{array}$ & $\begin{array}{l}\text { Proposed } \\
\text { LCVG with } \\
\text { Spectra }\end{array}$ & $\begin{array}{l}\text { 1Thick Spectra }{ }^{\circledR} \\
1 \text { Thin Spectra }{ }^{\circledR}\end{array}$ & $\begin{array}{l}0.0355 \\
0.0073\end{array}$ \\
\hline $\begin{array}{l}\text { ILC } \\
302\end{array}$ & $\begin{array}{l}\text { Water jacket } \\
\text { material } \\
\text { sample }\end{array}$ & $\begin{array}{l}1 \text { Urethane/Nylon } \\
1 \text { 20-mil /Urethane } \\
1 \text { Urethane/Nylon } \\
1 \text { thin Spectra }{ }^{\circledR}\end{array}$ & $\begin{array}{l}0.0240 \\
0.0301 \\
0.0242\end{array}$ \\
\hline $\begin{array}{c}\text { ILC } \\
303 a\end{array}$ & $\begin{array}{l}\text { Proposed } \\
\text { Restraint/ } \\
\text { Current } \\
\text { Bladder }\end{array}$ & $\begin{array}{l}1 \text { Woven Spectra }{ }^{\circledR} \\
1 \text { Urethane/Nylon }\end{array}$ & $\begin{array}{l}0.0112 \\
0.0240\end{array}$ \\
\hline $\begin{array}{c}\text { ILC } \\
303 b\end{array}$ & $\begin{array}{l}\text { Proposed } \\
\text { Restraint/ } \\
\text { Proposed } \\
\text { Bladder } \\
\end{array}$ & $\begin{array}{l}1 \text { Woven Spectra }{ }^{8} \\
1 \text { 10-mil LLPE }\end{array}$ & $\begin{array}{l}0.0112 \\
0.0231\end{array}$ \\
\hline $\begin{array}{c}\text { ILC } \\
304 a\end{array}$ & $\begin{array}{l}\text { Proposed } \\
\text { Restraint/ } \\
\text { Current } \\
\text { Bladder }\end{array}$ & $\begin{array}{l}\text { Spectra } \\
\text { Webbing }{ }^{\circledR} \\
1 \text { Urethane/Nylon }\end{array}$ & $\begin{array}{l}0.0333 \\
0.0244\end{array}$ \\
\hline $\begin{array}{c}\text { ILC } \\
304 b\end{array}$ & $\begin{array}{l}\text { Proposed } \\
\text { Restraint/ } \\
\text { Proposed } \\
\text { Bladder }\end{array}$ & $\begin{array}{l}1 \text { Spectra } \\
\text { Webbing }{ }^{\circledR} \\
1 \text { 10-mil LLPE }\end{array}$ & $\begin{array}{l}0.0333 \\
0.0228\end{array}$ \\
\hline
\end{tabular}

\section{TESTING PROCEDURES}

The improved understanding of the fabric transmission properties will allow redesign considerations to improve the spacesuit radiation safety. The basic penetration test is shown in figure 6 . The test is in principle quite simple; a low-energy proton beam is incident from the left on a swatch of the spacesuit test target as shown. The arrangement of the experimental setup is shown in fig. 7 . However, for the present testing, a collimator was not used. A reasonably uniform beam of protons is monitored by a $3 \mathrm{~mm}$ thick silicon detector (d3mm1). The transmitted spectrum through $\mathrm{d} 3 \mathrm{~mm} 1$ was measured in a "target out" test. The monitored beam passes through the target station and is analyzed by a set of position sensitive detectors (PSD1X\&Y) with total remaining energy detected by the $5-\mathrm{mm}$ silicon detector $(\mathrm{d} 5 \mathrm{~mm} 1)$ at the far right of the setup.

The baseline for the spacesuit TMG/LCVG lay-up is shown in figure 8 . To the far right of figure 8 is a single peak corresponding to the beam incident on the target. It is necessary to model this contribution well as it is critical 
to the interpretation of the target transmission properties. The second peak from the right is the protons transmitted through the fabric sections of the lay- up. The broadness of this second peak is related to the transmission properties of the fabric porosity and the height of the second peak relates to the fraction of the target not

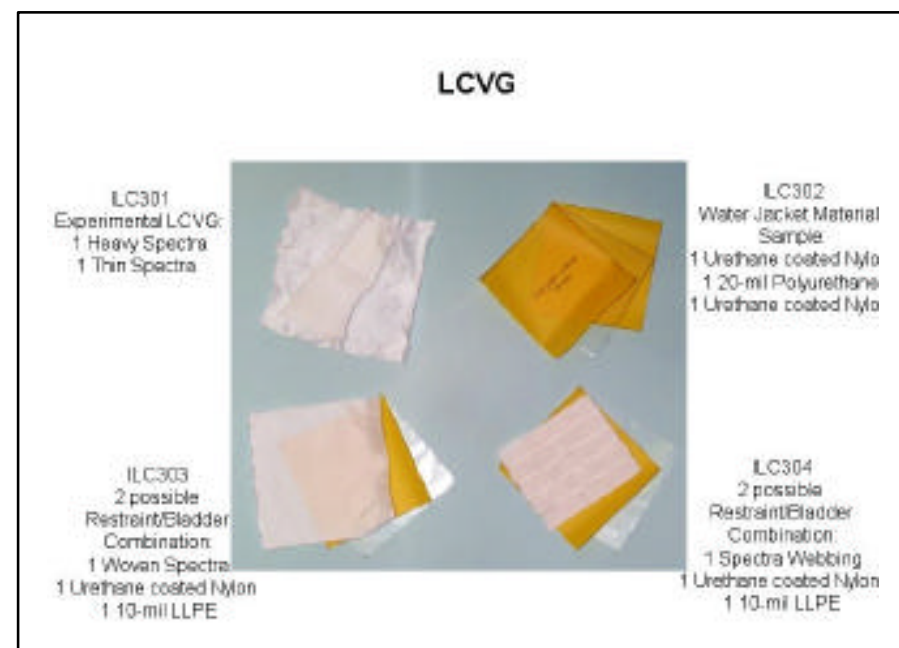

Fig. 5 LCVG material lay-ups as tested.

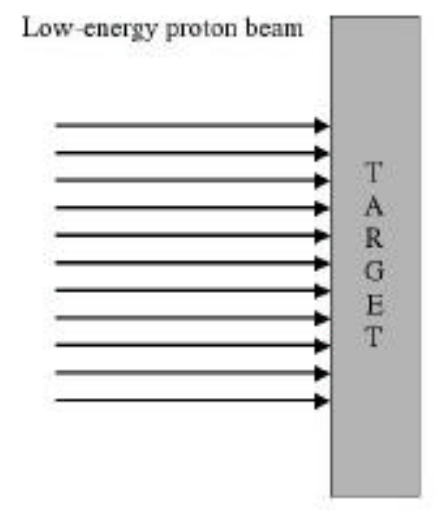

Fig. 6 Basic experimental test setup.

covered by the cooling tubes. The long central feature below $17 \mathrm{MeV}$ is characteristic of the transmission function of the water filled cooling tube. At the lower energies are structures related to multiple scattering effects. The present set of test objects will be easier to analyze since the single tubes stitched into the LCVG are replaced by either the LCVG target without tubes or the more uniform structure of the cooling vest.

The test matrix for the present study is given in table 5 . Each target contains the total material lay-up of the SSA with the outermost layer facing the beam and the innermost layer (closest to the skin) farthest from the beam. In targets representing the upper torso area, the lay-up includes an LCVG sample, the HUT fiberglass, and either the HUT TMG or the proposed TMG sample. In targets representing the arm assemblies and LTA, the lay- up includes an LCVG sample, a restraint/bladder sample, and a TMG sample. The test target combinations are ordered in the table from highest to lowest priority. Priority was given to replacement materials that could most reasonably be incorporated into a redesign of the SSA while maintaining existing material requirements. Priority was also given to replacement materials that would be expected to provide the greatest improvement to radiation protection in the SSA. This table also shows the beam energy or energies to which each test target was exposed. The testing will examine the protection value of lay-ups of alternate materials for various applications in the suit construction and fifteen tests in all are identified. The testing machine is the 88-inch cyclotron at the Lawrence Berkeley National Laboratory. The test apparatus is shown in figure 7 . The test objects will allow a relative comparison of current spacesuit technology and proposed improvements.

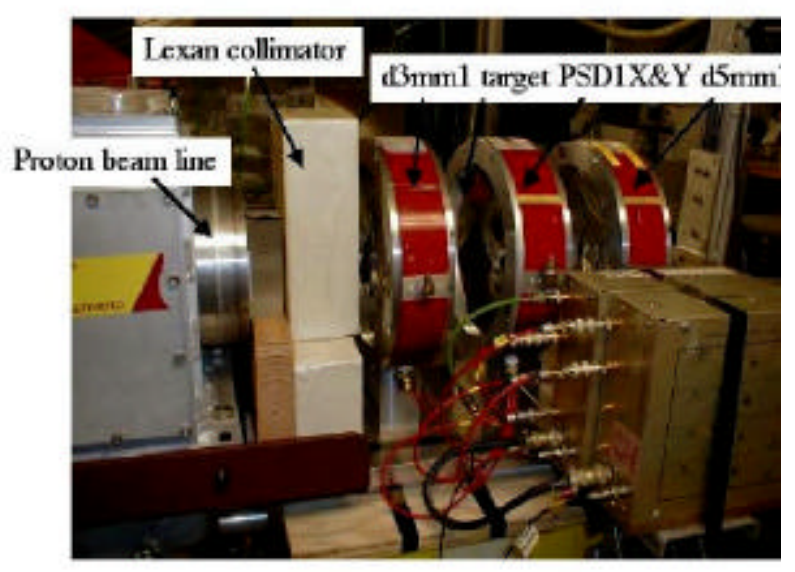

Fig. 7. Proton beamline used at the LBNL 88" cyclotron.

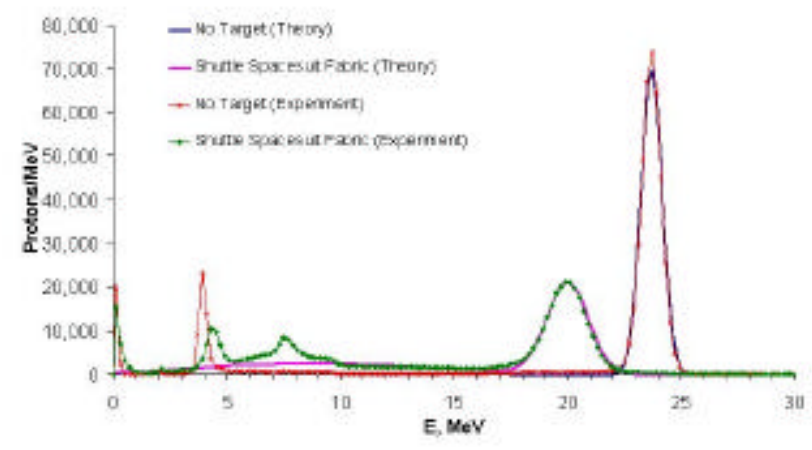

Fig. 8. Typical TMG/LCVG baseline results and analysis. 
Table 5 Material lay-up test matrix.

\begin{tabular}{|c|c|c|c|}
\hline Target & Lay-Up & Area of SSA & $\begin{array}{c}\text { Test Energy } \\
\text { MeV }\end{array}$ \\
\hline 1 & $102 / 101 / 301$ & HUT & 37,40 \\
\hline 2 & $203 / 102 / 301$ & HUT & $37 / 40$ \\
\hline 3 & $201 / 303 \mathrm{a} / 301$ & Arm/LTA & 37 \\
\hline 4 & $201 / 303 \mathrm{~b} / 301$ & Arm/LTA & 37 \\
\hline 5 & $203 / 303 \mathrm{a} / 301$ & Arm/LTA & 37 \\
\hline 6 & $203 / 303 \mathrm{~b} / 301$ & Arm/LTA & 37 \\
\hline 7 & $202 / 304 \mathrm{~b} / 301$ & Shoulder & 37 \\
\hline 8 & $203 / 101 / 302$ & HUT & $37 / 47$ \\
\hline 9 & $203 / 303 \mathrm{~b} / 302$ & Arm/LTA & $37 / 47$ \\
\hline 10 & $201 / 303 \mathrm{~b} / 302$ & Arm/LTA & $37 / 47$ \\
\hline 11 & $203 / 304 \mathrm{~b} / 302$ & Arm/LTA & 37 \\
\hline 12 & $203 / 304 \mathrm{~b} / 301$ & Arm/LTA & 37 \\
\hline 13 & $202 / 303 \mathrm{a} / 301$ & Shoulder & 37 \\
\hline 14 & $203 / 304 \mathrm{a} / 301$ & Arm/LTA & 37 \\
\hline 15 & $203 / 303 \mathrm{~b} / 302$ & Arm/LTA & 37,47 \\
\hline
\end{tabular}

\section{CONCLUSION}

In order to evaluate the radiation protection characteristics of some proposed new spacesuit materials, fifteen test target combinations of current and experimental spacesuit materials were exposed to a low energy proton beam at Lawrence Berkeley National Laboratory. Each target combination contained all of the necessary spacesuit layers; i.e. TMG, restrain/bladder or HUD fiberglass, and LCVG. Some of these target combinations accurately modeled the current Shuttle spacesuit. In others, new materials were substituted for one or more layers of the target combination. The new materials included low density linear polyethylene (LLPE) films substituted for the aluminized mylar in the TMG and the urethane coated nylon bladder currently in the suit. Spectra ${ }^{\circledR}$, a highdensity polyethylene fiber in knit and woven fabrics, was substituted for the LCVG nylon/Spandex net and nylon liner and the Dacron ${ }^{\circledR}$ restraint. Finally, a new water jacket concept, which more evenly distributes the water, was substituted for the LCVG. These materials were chosen because they are less porous than current materials and/or contain higher concentrations of hydrogen and therefore, should provide greater protection from radiation. The results from this experiment should show whether or not these new materials truly do provide more radiation protection than the current materials.

\section{REFERENCES}

1. Kosmos J.J., Nachtwey D.S., Hardy A. JSC/CTSDSS-241, 1-24-1989.

2. Wilson, J.W. et al. SAE 2001-01-2372.

3. Ross A.J. et al. NASA CP 3360, 1997. 